Research Article

\title{
Mesostructure Evolution of Gravelly Soil under the Triaxial Compressive Condition by Computerized Tomography
}

\author{
Yanli Wang $\mathbb{D}^{1}{ }^{1}$ Yong Wang $\mathbb{D}^{2}{ }^{2}{ }^{J i a j u n}$ Pan, ${ }^{1}$ and Rui Liang ${ }^{3}$ \\ ${ }^{1}$ Key Laboratory of Geotechnical Mechanics and Engineering of the Ministry of Water Resources, \\ Yangtze River Scientific Research Institute, Wuhan, Hubei 430010, China \\ ${ }^{2}$ State Key Laboratory of Geomechanics and Geotechnical Engineering, Institute of Rock and Soil Mechanics, \\ Chinese Academy of Sciences, Wuhan, Hubei 430071, China \\ ${ }^{3}$ Zienkiewicz Centre for Computational Engineering College of Engineering, Swansea University, Fabian Way, \\ Swansea SA1 8EN, UK
}

Correspondence should be addressed to Yong Wang; wang831yong@126.com

Received 27 October 2017; Revised 6 June 2018; Accepted 2 July 2018; Published 26 July 2018

Academic Editor: Jun Liu

Copyright (C) 2018 Yanli Wang et al. This is an open access article distributed under the Creative Commons Attribution License, which permits unrestricted use, distribution, and reproduction in any medium, provided the original work is properly cited.

Gravelly soil is widely used in many engineering construction projects, partly due to its extensive distribution and rich reserves in nature. Using special purpose loading equipment, the computerized tomography (CT) real-time tests were conducted to investigate the mesomechanical behavior of gravelly soil under the triaxial compressive condition. Mesostructure evolutions of soil particles, such as particle motion law and long axis direction, as well as the relation to macroscopic phenomenon were studied through the quantitative analysis of CT number and CT images. Results show that the mean CT number decreases, but the standard deviation increases with the increasing axial strain, which indicates that internal structural defects of gravelly soil are intensified in the loading process. Position adjustment and long axis evolution of particles reflect behaviors of particle rearrangement and anisotropism development during the triaxial compressive process. Experimental findings are helpful to revealing the mesomechanism of deformation of gravelly soil.

\section{Introduction}

Based on the Specification of Soil Test (SL237-1999) of China, coarse-grained soil refers to a soil with over $50 \%$ mass ratio of $0.075 \mathrm{~mm}-60 \mathrm{~mm}$ particles. Gravelly soil is referred to coarse-grained soil in which the gravel particles (the size is greater than $2 \mathrm{~mm}$ ) have a mass greater than $50 \%$ of the total mass. Being extensively distributed and available in nature, gravelly soil is widely used in engineering construction because it has a characteristic of strong compression, water permeability, high filling density, shear strength, minimal settlement, and high bearing capacity [1]. Due to these favorable qualities, the gravelly soil serves as the main construction material of earth-rock dams. However, with a sharp increase of desired dam height and the complexity of stress conditions, traditional understanding of gravelly soil is inadequate for designing modern earth-rock dams that have increased heights. Strength and deformation characteristics of gravelly soil are basic properties considered for the engineering design of earth-rock dams. Due to uneven shapes and sizes, as well as random distribution of particles, gravelly soils have discrete characteristics of multiscale, forming spatial multiscale structures [2-4]. In addition, the particle breakage features under high-stress conditions seriously affect the stress-strain behaviors, strength, and deformation properties. Furthermore, due to their mechanism complexities, such as nonlinearity, elastic-plastic property, volume dilatancy, and anisotropism, the gravelly soil is difficult to be studied in-depth from the perspective of continuum mechanics. In recent years, some scholars began to investigate the microscopic mechanical properties of gravelly soil. They believed that macroscopic deformation failure results from the accumulation of microscopic structural deformations. Hence, a better law of microstructure 
evolution could give further scientific explanations to engineering failures of earth-rock dams. In addition, the technique of X-ray computerized tomography (CT) imaging has been well developed, which has been used to visualize and quantify the soil structure at different scales based on its reliable and nondestructive evaluation of images at a high resolution $[5,6]$. With the help of CT technology, some investigations were conducted to perform the material microstructure analysis [7-10], including physical density and void ratio measurement [11-15], determining the aggregate size distribution of soil [16], and the numerical model establishment of geotechnical materials [17]. Meanwhile, some research achievements on the mesodeformation mechanism of granular materials have been performed by using CT technology. For example, Chang et al. [18] developed an algorithm that links the particle identity at different load steps in a triaxial specimen using CT. Wang et al. [19] evaluated the potential of CT to reconstruct a 3D digital representation of granular particles. Alshibli and Alramahi [20] conducted a microscopic evaluation of strain distribution in granular materials, which consists of $6.5 \mathrm{~mm}$ spherical plastic particles under an axisymmetric loading condition. Cheng et al. [21] carried out a series of straincontrolled triaxial tests of granular materials by the first generation, independently developed CT triaxial apparatus and preliminarily achieved the movement law of particle of granular materials during the triaxial test. Watanabe et al. [22] studied the displacement in sand under triaxial compression by tracking soil particles on the X-ray CT number. Sun et al. [23] investigated the conditions of mesoscale failure in the backfill body in a subsidence area under uniaxial compression tests by adopting CT scanning. However, these researches only focused on sand and granular materials with regular shape, and very few work has been done on the mesodeformation mechanism of the gravelly soil.

In this study, a series of triaxial compression tests are conducted on gravelly soil using the latest developed CT triaxial apparatus. The mesostructure evolution of gravelly soil specimens in the process of triaxial test is investigated in detail. The outline of the paper is as follows. Section 2 explains the details of the experimental method and procedure. In Section 3, a quantitative analysis on the CT number and images is performed. Some concluding remarks are stated in Section 4 . Also, by performing a quantitative analysis on the CT number and images, the displacement and orientation of gravelly soil particles and their relation to the macroscopic phenomenon are studied.

\section{Experimental Methods}

2.1. Test Apparatus. The CT 3D visualization system for mechanical testing of rock and soil developed by the Yangtze River Scientific Research Institute of China is applied in this study. As shown in Figure 1, the system is composed of an $\mathrm{X}$-ray CT scanner, and a triaxial apparatus is used for CT scanning. The CT scanner, SOMATOM Sensation $40 \mathrm{CT}$ imaging system, adopts helical scanning and high-efficiency syngo postprocessing software for fast reconstruction of images.

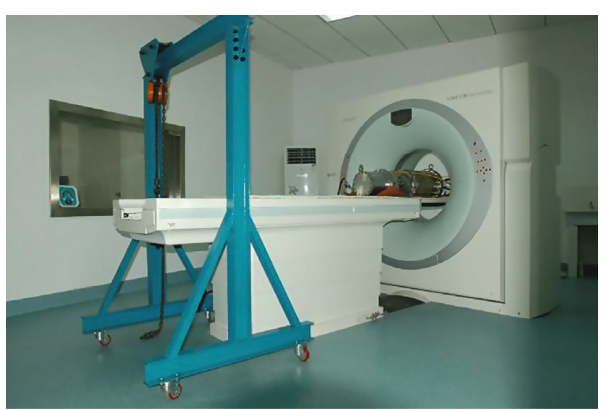

FIgURE 1: X-ray CT visualization system.

It can capture high-resolution images of any part of an object through profile scanning and $3 \mathrm{D}$ renderings and produce $\mathrm{CT}$ values that can be analyzed for the purpose of the mesostructure property of gravelly soils. The CT triaxial apparatus is the second generation of the horizontal CT triaxial apparatus developed by the Yangtze River Scientific Research Institute of China (Figure 2). Either stress or strain control mode can be chosen as the loading mode. The stress-control mode employs a high-pressure energy storage tank, whereas the strain-control mode uses stepping motor control. A gas-water conversion unit is adopted to protect long-term stabilization of confining pressure. The jack is a metal component, and the pull rod of the pressure chamber is made of a special aluminum alloy, which can effectively reduce the artifacts. The size of the specimen is $200 \mathrm{~mm}$ in height and $100 \mathrm{~mm}$ in diameter, and the maximum confining pressure and maximum axial load are $1.0 \mathrm{MPa}$ and $100 \mathrm{kN}$, respectively.

2.2. Sample Preparation and Test Methods. Test materials are collected from the II stockyard of Shitou Gorge Hub Dam under construction in Menyuan County, Qinghai Province of China. Gravels and sands are separated before preparing test specimens. Soil specimens are successively filtered by $20 \mathrm{~mm}, 10 \mathrm{~mm}, 5 \mathrm{~mm}, 2 \mathrm{~mm}$, and $1 \mathrm{~mm}$ sieves after being dried. In order to clearly observe the motion feature of soil particles in the process of triaxial compression, $10 \mathrm{~mm}-$ $20 \mathrm{~mm}$ single-graded gravels are used as test materials. Gravel particles are elliptical without sharp and flaked edges. The remolded specimens were prepared by the multilevel wet pounding method with the size of $100 \mathrm{~mm}$ (diameter) $\times$ $200 \mathrm{~mm}$ (height), and the basic indexes are as follows. The specific gravity $\left(G_{\mathrm{s}}\right)$ is 2.70 , dry density $\left(\rho_{\mathrm{d}}\right)$ is $1.8 \mathrm{~g} / \mathrm{cm}^{3}$, and void ratio $(e)$ is 0.5 . First, a saturated triaxial consolidation draining shear test is conducted by using the traditional fullautomatic triaxial apparatus to obtain the strength and deformation characteristics of the gravelly soils. The specimen was fully saturated by hydraulic saturation method when the $B$ value that was typically greater than 0.95 . The specimens were isotropically consolidated under an effective confining stress equal to $100 \mathrm{kPa}, 200 \mathrm{kPa}, 300 \mathrm{kPa}$, and $400 \mathrm{kPa}$, respectively. The standard of isotropical consolidation can be deemed to be reached when the volumetric change of the specimen remains invariable for 5 minutes. Then a strain-controlled monotonic shear load was applied under the drained condition to obtain 


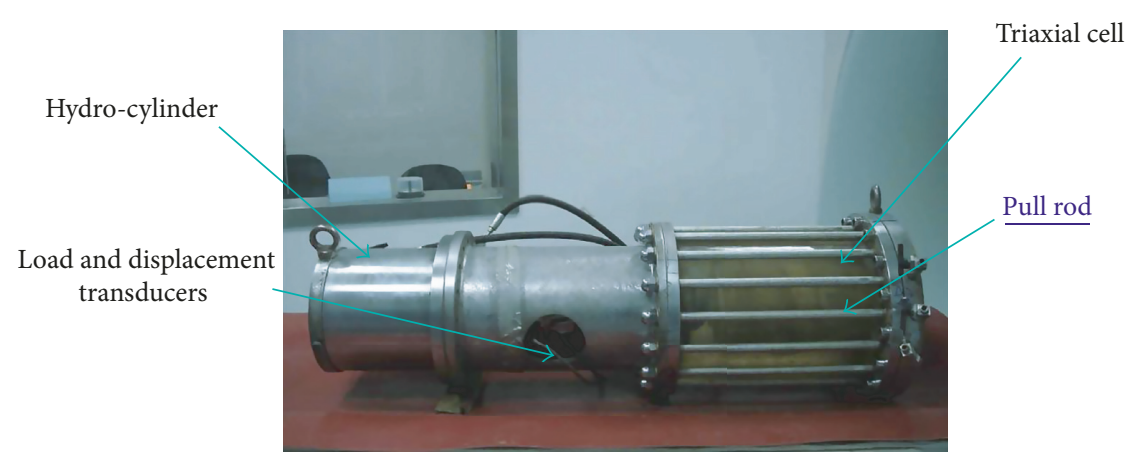

Figure 2: CT triaxial apparatus.

the strength and deformation behavior of gravelly soil. The monotonic shear load was applied at a rate of $0.4 \mathrm{~mm}$ per minute. Second, a CT triaxial test of typical gravelly soil is carried out with fixed confining pressure $(200 \mathrm{kPa})$ by the CT triaxial apparatus. The specimens are prepared on the CT triaxial apparatus, which is placed on the mobile platform of the CT visualization system for the strain-controlled CT triaxial test. Real-time CT scanning is achieved when the axial strain level reaches a value of $1.2 \%$, and when the loading is finished, the soil specimen is scanned again. This scanning is repeated at the axial strain levels of $2.2 \%, 3.2 \%, 4.2 \%, 5.2 \%$, $6.2 \%, 7.2 \%, 8.2 \%, 9.2 \%, 11.7 \%, 13.1 \%$, and $15.8 \%$, respectively. Scanning parameters of the CT scanner are as follows. The voltage and current are $140 \mathrm{kV}$ and $500 \mathrm{~mA}$, respectively. The layer thickness is $0.6 \mathrm{~mm}$ in the test, and the reconstruction matrix was $512 \times 512$. Sketch of different scanning positions of the test sample after $3 \mathrm{D}$ reconstruction are shown in Figure 3. The cross section (marked 1) and vertical section (marked 2) of the middle test sample are selected to be analyzed. Meanwhile, the corresponding axial strains and volume strains of conventional triaxial tests are recorded. The CT number and CT images of typical sections of CT triaxial tests are obtained through $3 \mathrm{D}$ reconstruction to study mesostructure evolutions of gravelly soils under the triaxial compressive condition.

\section{Results and Discussion}

3.1. Conventional Triaxial Tests. The deviatoric stress versus axial strain curve and the volumetric strain versus axial strain curve of gravelly soil under the draining consolidation condition are shown in Figure 4(a) and Figure 4(b), respectively. $\sigma_{1}$ and $\sigma_{3}$ are the axial stress and radial stress, respectively, and $\varepsilon_{\mathrm{v}}, \varepsilon_{\mathrm{a}}$ are the volumetric strain and axial strain, respectively. As can be seen from Figure 4(a), the gravelly soil presents strainhardening properties under the draining consolidation condition. With the increase of confining pressure, deviatoric stress increases significantly. Meanwhile, the volume dilatancy trend of typical gravelly soils can be observed in Figure 4(b) under a lower confining pressure.

\subsection{CT Triaxial Tests}

3.2.1. Analysis for the Vertical Section. Figure 5 shows the CT images of the vertical section of the test sample

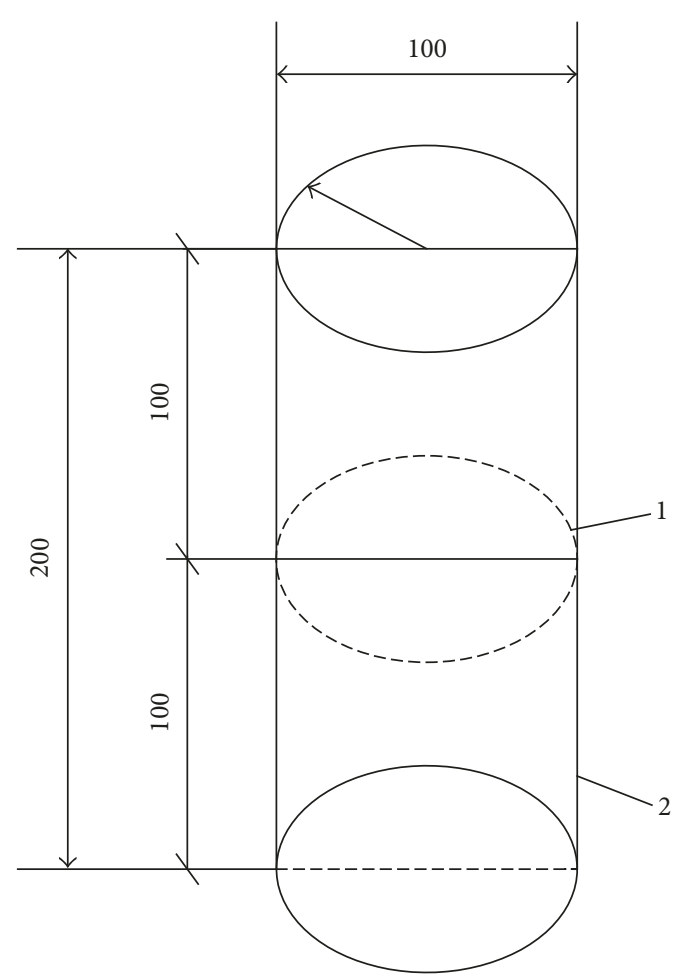

1: cross section

2: vertical section

FIGURE 3: Sketch of the scanning position of the soil sample (unit: $\mathrm{mm}$ ).

$\left(\sigma_{3}=200 \mathrm{kPa}\right)$ at different strain levels. For particle aggregates, particles of different shapes embed and contact mutually and form a stable structural system after the vibration compaction. Due to the uneven size of particles, there are some evidently hollow parts. Particle positions and long axis directions distribute randomly. The local void structures become more evident at the axial strain level of $4.2 \%$, such as the particles in the circular frame in Figure 5. Particle breakages, such as the particles in the oval frame, have already occurred in the initial state, which is caused by sample compaction. When axial strain increases to $5.2 \%$, the broken particles are more clearly observed, such as the particles in the oval frame. As loading continues, broken particles are further separated, but they still can bear the 


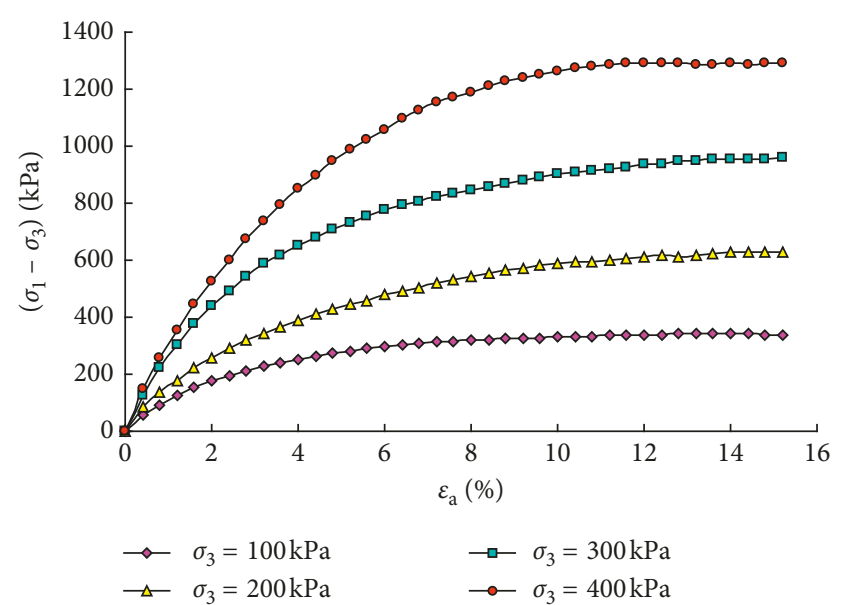

(a)

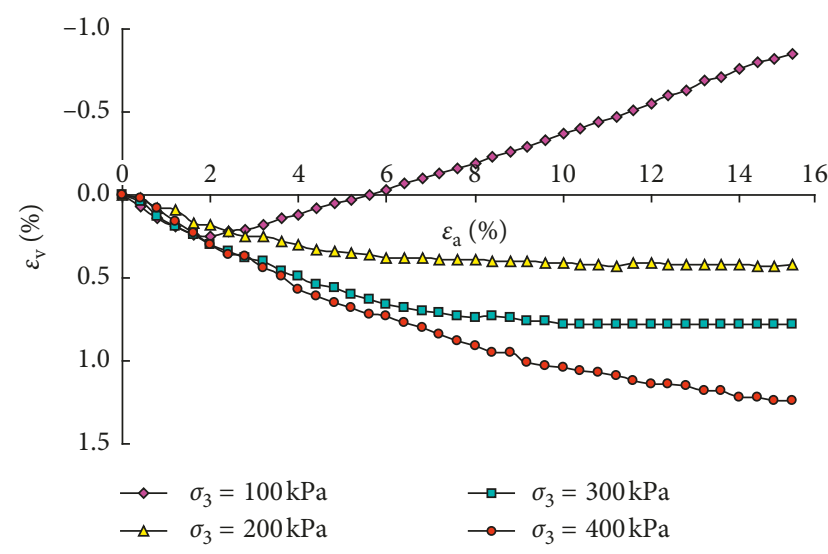

(b)

FIGURE 4: Relationship between stress and strain of typical gravelly soils.

strong contact stress. The upper particles move downward, and some small broken particles occupy voids gradually, such as the particles in the square frame of Figure 5. Subsequently, the particles move downward continuously, and the broken particles are adjusted to new positions gradually. The mutual contact relation of the particles changes so that the test sample produces large vertical displacement.

3.2.2. Analysis for the Cross Section. Figure 6 shows the CT images of the cross section of the test sample $\left(\sigma_{3}=200 \mathrm{kPa}\right)$ at different axial strains. Obvious changes are observed between initial and final CT images of the cross section, which indicates that the particle position has been adjusted greatly and the test sample produces large radial displacement. Particle breakages, such as the particles in the oval frame, have already occurred in the initial state, which can be seen in the vertical section of the test sample. When the axial strain increases to $4.2 \%$, radial motion of particles changes slightly, yet particle breakage is not very serious. When the strain increases to $8.2 \%$, broken particles move to new positions and particle breakage further develops. Broken particles generate great radial motion and enter into intact particles, thus resulting in large radial displacement of the test sample.

3.2.3. CT Numbers of the Vertical and Cross Sections. CT technology conducts rotary scanning by X-ray penetration through the object section and collects information after different material attenuations of the X-ray. After amplification and analog-to-digital conversion, the computer makes spatial calculations to rays of different directions, correlated with a point in the space within the detection space scope of CT, thus getting the CT number directly related to the $\mathrm{X}$-ray absorptivity of the point $(\mu)$. As a result, a $\mu$ digital image of the object is formed. Hounsfield [24] established the standard equation of a medical CT machine as

$$
H_{\mathrm{rm}}=1000 \times \frac{\mu_{r m}-\mu_{w}}{\mu_{w}},
$$

where $H_{\mathrm{rm}}$ is the CT number of a material, $\mu_{\mathrm{rm}}$ is the X-ray absorptivity of substance at an image point, and $\mu_{w}$ is the X-ray absorptivity of pure water.

If the measured substances are the same type of material, only the density changes. The X-ray absorption coefficient of the test substance can be expressed as

$$
\mu_{\mathrm{rm}}=\mu_{\mathrm{m}} \rho,
$$

where $\mu_{\mathrm{m}}$ refers to the mass absorption coefficient of a substance and $\rho$ is the density of a substance.

Material density could be calculated from the CT number of the material once the statistical law of the CT number and material density are disclosed:

$$
\rho=\frac{\mu_{\mathrm{w}} \cdot\left(\left(H_{\mathrm{rm}} / 1000\right)+1\right)}{\mu_{\mathrm{m}}} .
$$

It can be known from (3) that the CT number represents material density directly, and the mean CT number of a region reflects the mean density of all material points in the region, providing $\mu_{\mathrm{rm}}$ is given. The standard deviation of the CT number of a certain confidence level reflects the uniformity coefficient of density of material points in the region directly and reflects the structural strength of the region indirectly $[25,26]$. With the development of internal defects of soil (e.g., cracks and gaps), the mean CT number decreases, while the standard deviation of the CT number increases [27, 28].

The relation curves of the mean CT number of vertical sections and cross sections versus axial strain are shown in Figure 7. The mean CT number of all the specimens decreases when axial strain increases, indicating that the mean density of specimens decreases and internal defects increase during the loading process. It shows that gaps increase and particle breakage intensified inside the specimens. The relation curves of the standard deviation of the CT number of vertical sections and cross sections versus axial strain are shown in Figure 8. The standard deviation of the CT number is positively correlated with axial strain, indicating that the uniformity degree of specimens increases and internal structural damages of gravelly soils 


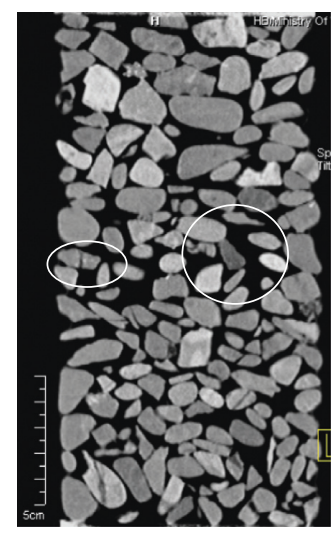

(a)

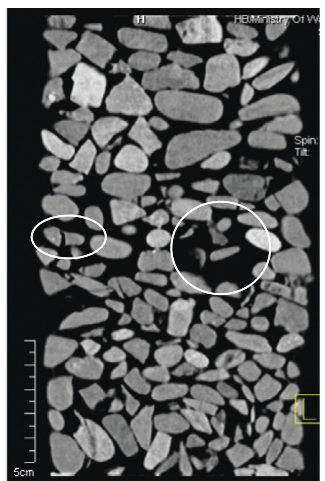

(e)

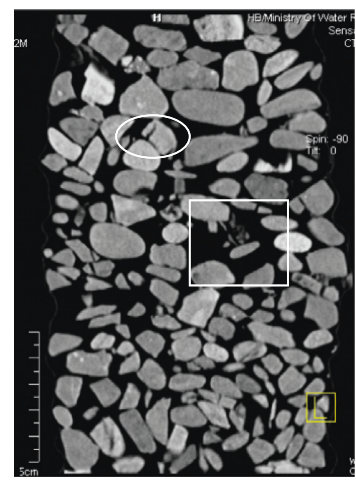

(i)

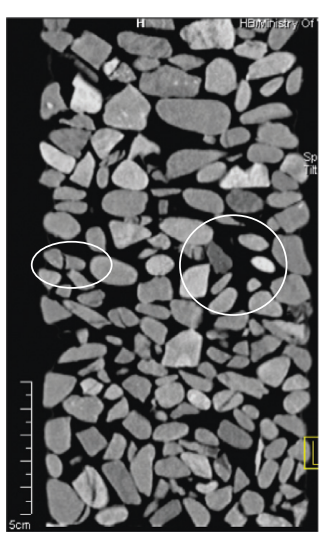

(b)

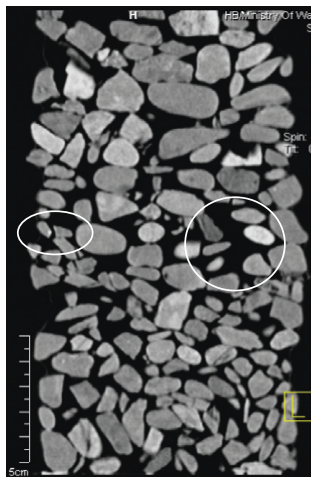

(f)

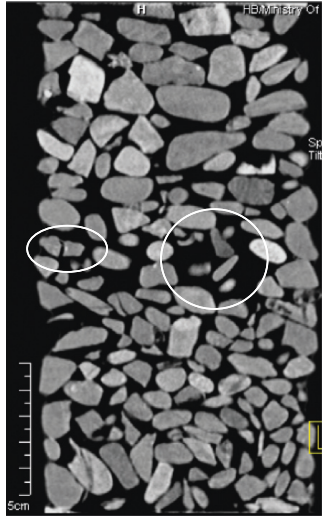

(c)

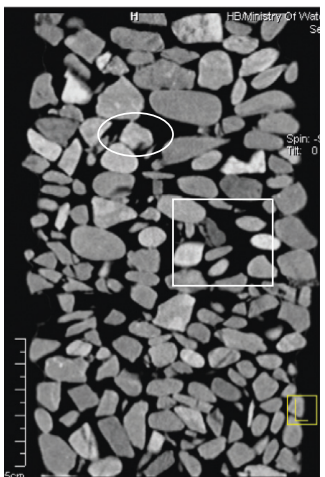

(g)

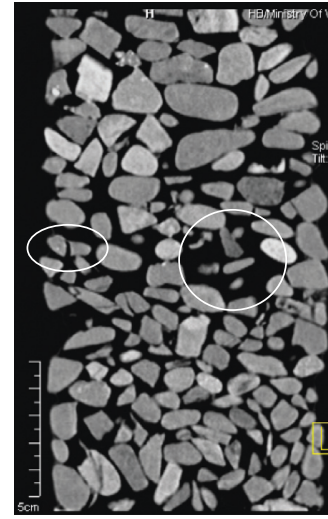

(d)

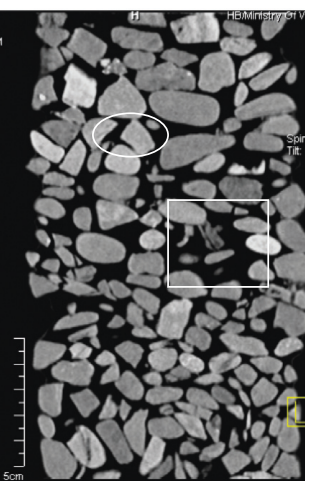

(h)

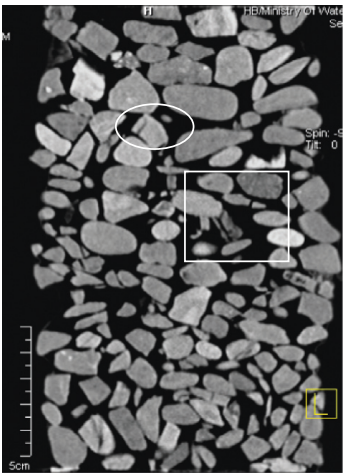

(j)

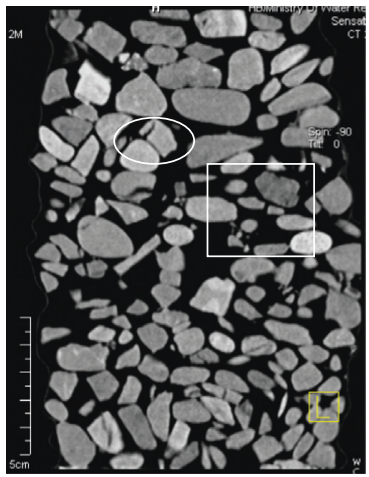

(k)

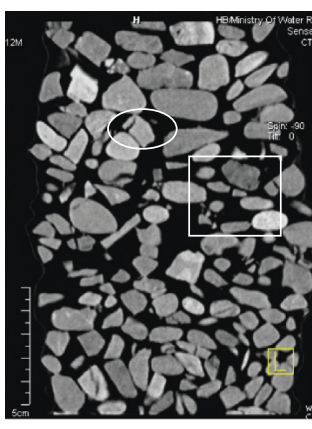

(1)

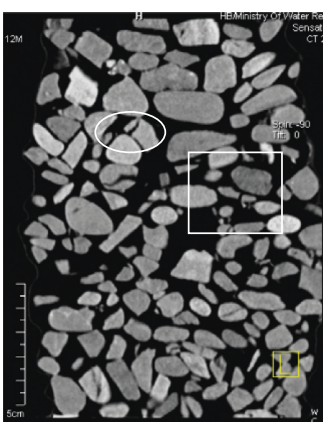

(m)

FIGURE 5: Vertical sectional images of the test sample $\left(\sigma_{3}=200 \mathrm{kPa}\right.$ ). (a) Initial. (b) $\varepsilon_{\mathrm{a}}=1.2 \%$. (c) $\varepsilon_{\mathrm{a}}=2.2 \%$. (d) $\varepsilon_{\mathrm{a}}=3.2 \%$. (e) $\varepsilon_{\mathrm{a}}=4.2 \%$. (f) $\varepsilon_{\mathrm{a}}=5.2 \%$. (g) $\varepsilon_{\mathrm{a}}=6.2 \%$. (h) $\varepsilon_{\mathrm{a}}=7.2 \%$. (i) $\varepsilon_{\mathrm{a}}=8.2 \%$. (j) $\varepsilon_{\mathrm{a}}=9.2 \%$. (k) $\varepsilon_{\mathrm{a}}=11.7 \%$. (l) $\varepsilon_{\mathrm{a}}=13.1 \%$. (m) $\varepsilon_{\mathrm{a}}=15.8 \%$. 


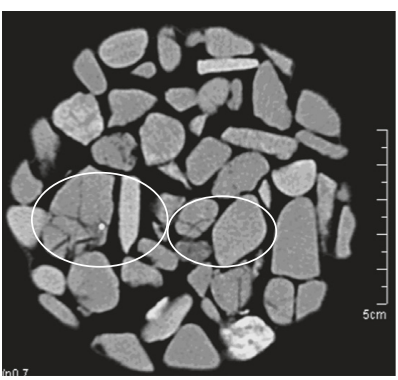

(a)

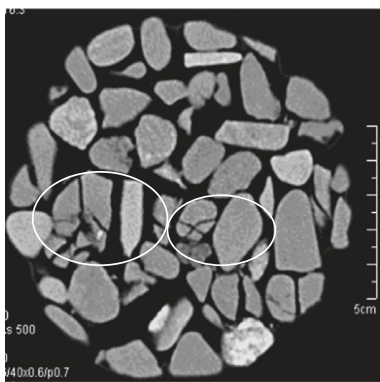

(e)

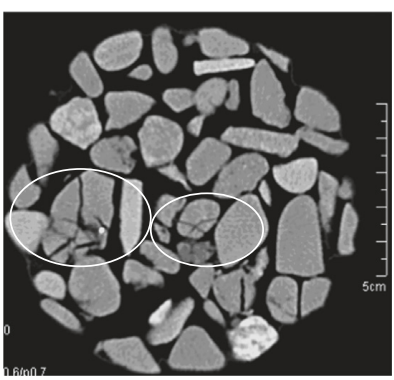

(b)

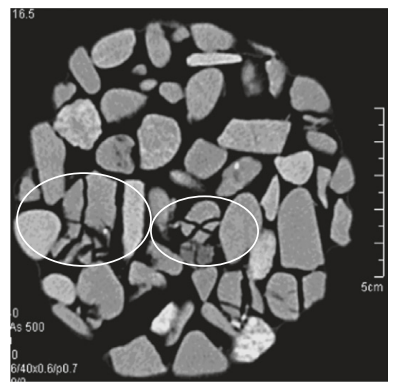

(f)

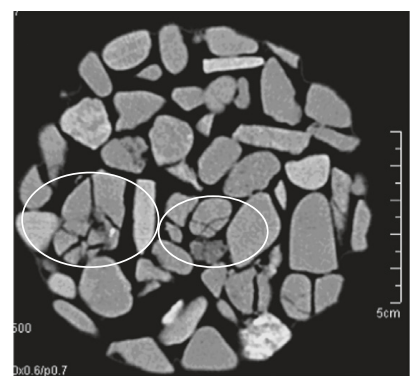

(c)

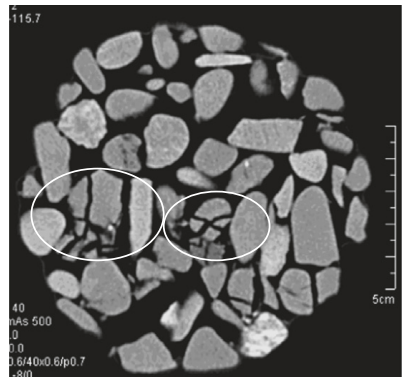

(g)

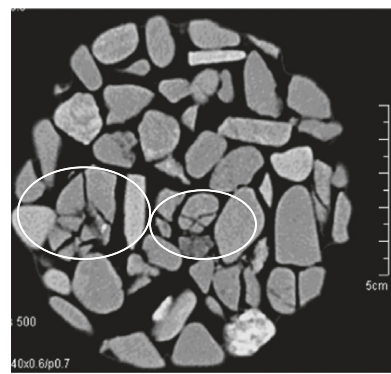

(d)

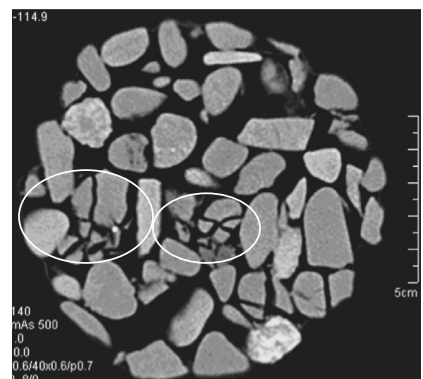

(h)

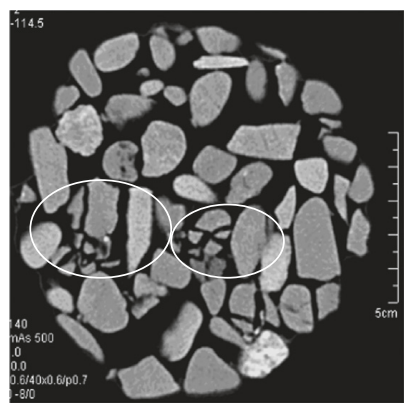

(i)

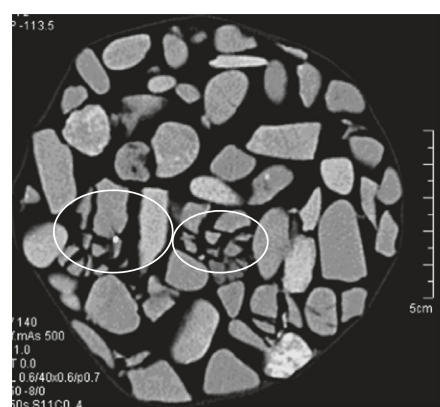

(j)

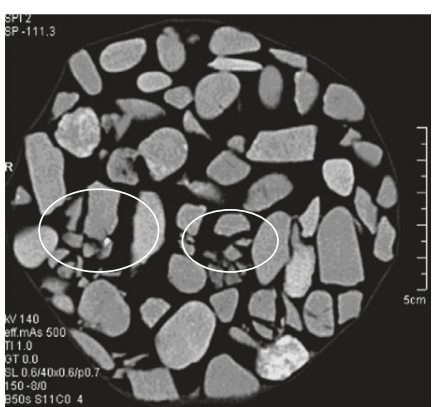

$(\mathrm{k})$

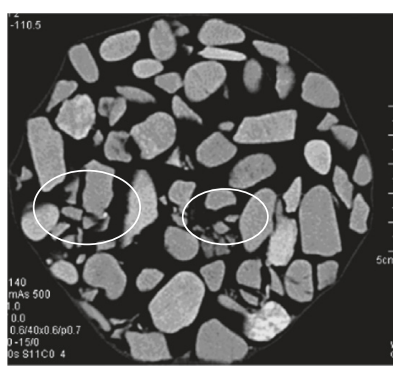

(1)

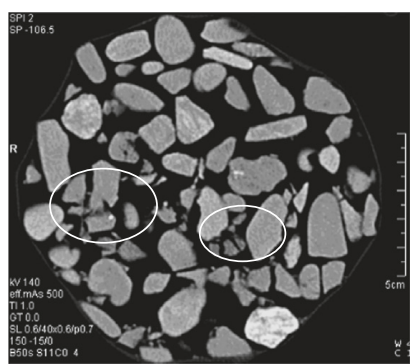

(m)

Figure 6: Cross-sectional images of the test sample $\left(\sigma_{3}=200 \mathrm{kPa}\right.$ ). (a) Initial. (b) $\varepsilon_{\mathrm{a}}=1.2 \%$. (c) $\varepsilon_{\mathrm{a}}=2.2 \%$. (d) $\varepsilon_{\mathrm{a}}=3.2 \%$. (e) $\varepsilon_{\mathrm{a}}=4.2 \%$. (f) $\varepsilon_{\mathrm{a}}=5.2 \%$. (g) $\varepsilon_{\mathrm{a}}=6.2 \%$. (h) $\varepsilon_{\mathrm{a}}=7.2 \%$. (i) $\varepsilon_{\mathrm{a}}=8.2 \%$. (j) $\varepsilon_{\mathrm{a}}=9.2 \%$. (k) $\varepsilon_{\mathrm{a}}=11.7 \%$. (l) $\varepsilon_{\mathrm{a}}=13.1 \%$. (m) $\varepsilon_{\mathrm{a}}=15.8 \%$.

intensify during the loading process. The relationships between mean CT number and standard deviation of the CT number versus axial strain reflect the results of CT images well.

\subsubsection{Analysis for the Particle Motion}

(1) Particles Displacement. The displacement vector of particles in CT images under different macroscopic strain states of the triaxial test are measured by the image processing system. The bottom center of the specimen is taken as the origin of coordinates. The horizontal direction is the $x$-axis (positive rightward) and vertical direction is the $y$-axis (positive upward). The displacement vectors of particles in the vertical section of the CT image from $0 \%$ to $6.2 \%$ and from $6.2 \%$ to $15.8 \%$ axial strain are shown in Figure 9. When the axial strain increases from 0 to $6.2 \%$, large vertical displacement of particles appears. However, particles in different parts of the specimen have different displacement laws, accompanied with particle dislocation. Upper particles of the sample produce the largest displacements, 


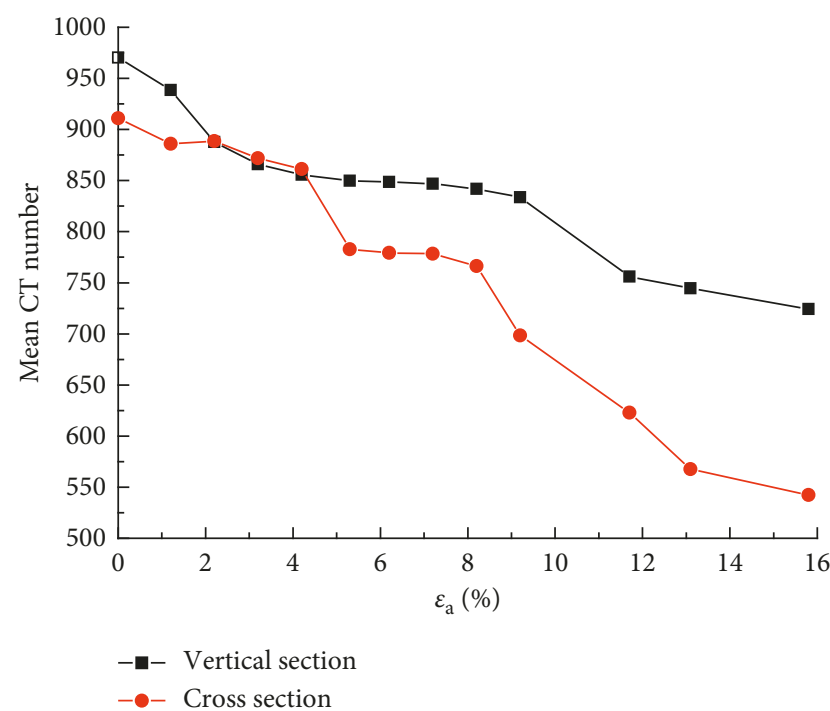

FIgURE 7: Relationships between the mean CT number and axial strain.

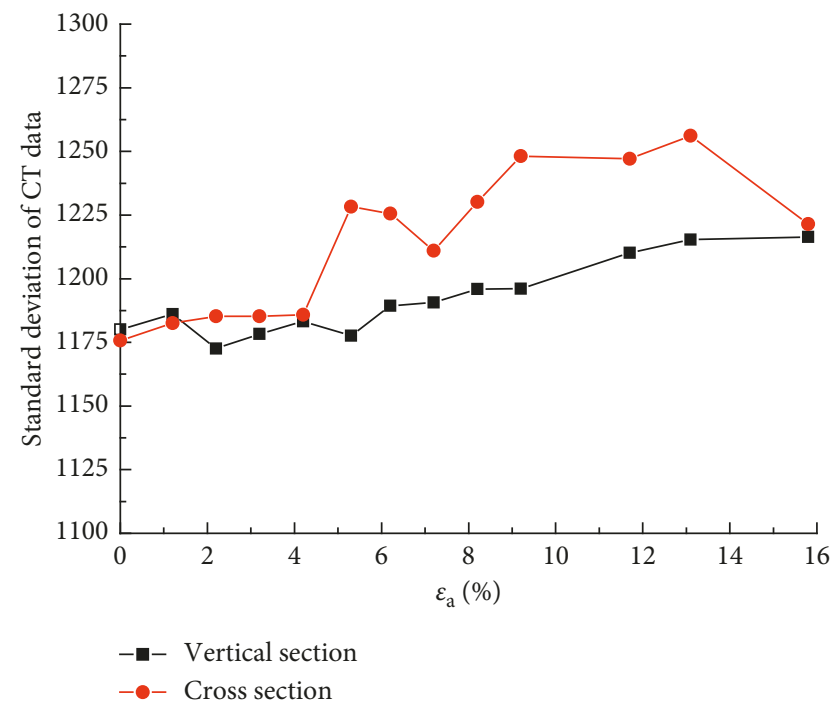

FIgURE 8: Relationships between the standard deviation of the CT number and axial strain.

followed by middle particles and bottom particles, successively. The maximum vertical displacement reaches $14.77 \mathrm{~mm}$. It is because the upper part of the test specimen is the loading end that has larger overall displacement, while the bottom is the fixed end where the particle displacement and dislocation are minimal. Moreover, the horizontal displacements of particles at different heights are different. Horizontal displacements of particles within a certain upper and bottom range are very small. Maximum horizontal displacement of particles increases gradually approaching the middle height of the specimen. The maximum horizontal displacement reaches $6.80 \mathrm{~mm}$. When axial strain increases from $6.2 \%$ to $15.8 \%$, the vertical displacements of the upper particles further increase, while the displacements of the bottom particles are not visible to the human eye. Horizontal displacements of particles at the middle

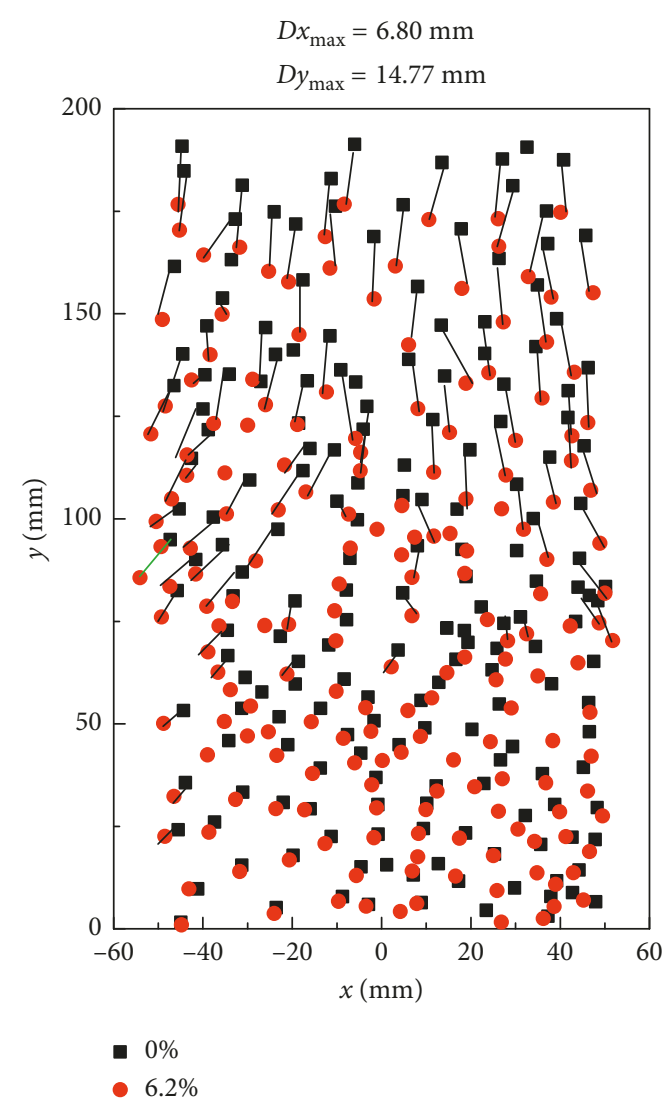

(a)

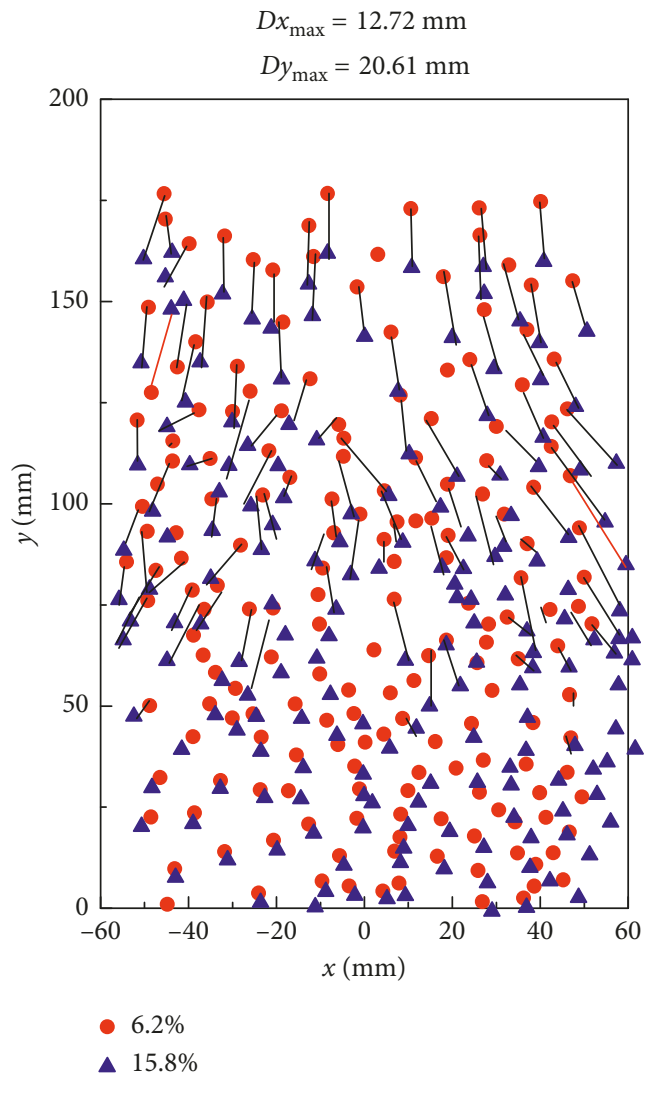

(b)

FIgURE 9: Displacement vector picture of particles. 


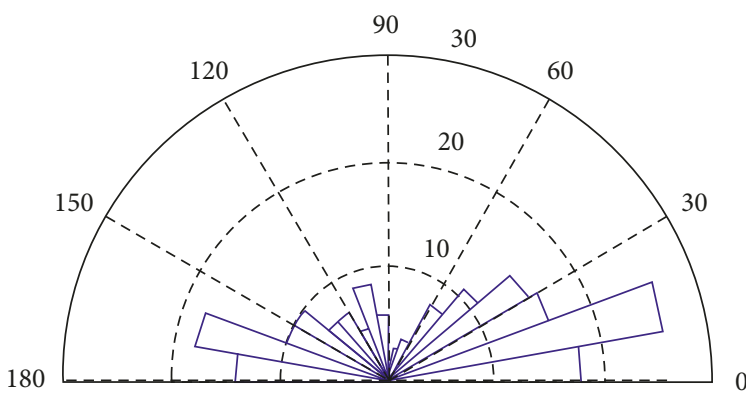

(a)

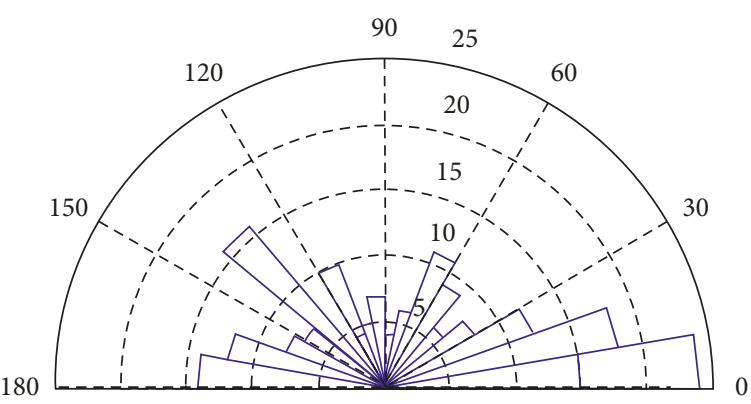

(b)

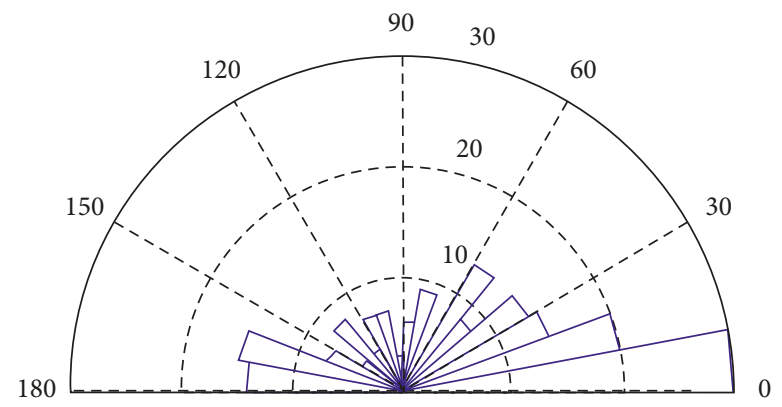

(c)

FIGURE 10: Rose diagrams of long axis orientation evolution. (a) $\varepsilon_{\mathrm{a}}=0 \%$. (b) $\varepsilon_{\mathrm{a}}=6.2 \%$. (c) $\varepsilon_{\mathrm{a}}=15.8 \%$.

height of the specimen further increase, while the upper and bottom particles remain constant. The maximum horizontal and vertical displacements reach $12.72 \mathrm{~mm}$ and $20.61 \mathrm{~mm}$, respectively. Particles at the same horizontal coordinate or vertical coordinate generate different displacement, which shows that the position adjustment of the particles is not homogeneous. In the process of triaxial compression, larger position adjustment or particle breakage occurs in parts of the particles due to the change of contact stress state. This part of the adjusted particles caused the adjacent particle positions to rearrange and the contact state to change, then further position adjustment of the adjacent particles or particle breakage occurs. Such a chain reaction between particles causes the mesostructure evolution of gravelly soil under the triaxial compressive condition.

(2) Particle Orientation. Particle orientation reflects particle rearrangement during the triaxial compressive process. Figure 10 is the rose diagram of particle evolution along the long axis at three typical strains $(0 \%, 6.2 \%$, and $15.8 \%)$. As shown in Figure 10 , the long axis prefers to be $15^{\circ}$ with the horizontal direction at the initial state because of sample compaction. When the axis strain is $6.2 \%$, the long axis prefers to be horizontal. When the axis strain is $15.8 \%$, particles rearrange and the long axis even prefers to be horizontal, but the degree is strengthened. It reflects that particles produce both translational and rotational deformations during the triaxial compressive process. In fact, the deformation process of gravelly soil is a process of relative sliding, rotating, crushing, and recombination of particles. Study on the law of particle motion and its structural changes in the process of triaxial compression can help us to better understand the mesodeformation mechanism of gravelly soils.

\section{Conclusions}

With the help of the advanced CT technology, real-time tracking and position scanning tests of gravelly soil specimens in the process of triaxial compressive conditions are conducted in this study. Based on the quantitative analysis of CT numbers and CT images, laws of particle motion and mesostructure evolution characteristics were investigated. Some conclusions can be drawn as follows:

(1) As the axial strain increases, the mean CT number decreases, but the standard deviation increases. This indicates that internal structural defects of gravelly soil are intensified in the loading process, along with the macroscopic decrease of mean density and the increase of the uniformity coefficient.

(2) Under a certain strain state, position adjustment of particles in different parts of a soil sample differs significantly. Particles in the upper part achieve the maximum vertical displacement, and particles in the middle have the largest radial displacement, while particles close to the bottom present minimal displacement.

(3) Long axis evolution of particles reflects particle rearrangement during the triaxial compressive process. It reflects that particles produce both translational and rotational deformations during the triaxial compression.

Computerized tomography (CT) real-time tests are helpful to revealing the mesomechanism of deformation of gravelly soil. In order to determine the mechanical 
properties of gravelly soil, more quantitative information such as pore change and particle breakage about the strain field is required. In this study, the particles motion during the triaxial compressive process is emphatically investigated. It should be noted that it is not enough to reveal the mesoscopic mechanism of gravelly soil. Further quantitative studies will focus on the information of pore change and particle breakage.

\section{Conflicts of Interest}

The authors declare that they have no conflicts of interest.

\section{Acknowledgments}

The authors gratefully acknowledge the financial support from the National Natural Science Foundations of China (51779017, U1765203, and 51579237), the Natural Key R\&D Program of China (2017YFC0404804), and the Foundation of Yangtze River Scientific Research Institute in China (CKSF2015051/YT, CKSF2017023/YT, and CKSF2016272/YT).

\section{References}

[1] Q. G. Guo, Engineering Properties and Application of Gravelly Soil, Yellow River Water Conservancy Press, Zhengzhou, China, 1999.

[2] A. Tordesillas, "Force chain buckling unjamming transitions and shear banding in dense granular assemblies," Philosophical Magazine, vol. 87, no. 32, pp. 4987-5016, 2007.

[3] A. Tordesillas, J. Zhang, and R. Behringer, "Buckling force chains in dense granular assemblies: physical and numerical experiments," Geomechanics and Geoengineering, vol. 4, no. 1, pp. 3-16, 2009.

[4] C. S. Willson, N. Lu, and W. J. Likos, "Quantification of grain, pore, and fluid microstructure of unsaturated sand from X-ray computed tomography images," Geotechnical Testing Journal, vol. 35, no. 6, pp. 1-13, 2012.

[5] M. Lamande, D. Wildenschild, F. E. Berisso et al., "X-ray CT and laboratory measurements on glacial till subsoil cores: assessment of inherent and compaction-affected soil structure characteristics," Soil Science, vol. 178, no. 7, pp. 359-368, 2013.

[6] A. Garbout, L. J. Munkholm, and S. B. Hansen, "Temporal dynamics for soil aggregates determined using X-ray CT scanning," Geoderma, vol. 204-205, no. 4, pp. 15-22, 2013.

[7] J. Desrues, R. Chambon, M. Mokni, and F. Mazerolle, "Void ratio evolution inside shear bands in triaxial sand specimens studied by computed tomography," Géotechnique, vol. 46, no. 3, pp. 529-546, 1996.

[8] K. Tani, "X-ray computed tomography technique to observe shear banding in dense sands," in Proceedings of International Symposium on Deformation and Progressive Failure in Geomechanics, pp. 315-320, Nagoya, Japan, October 1997.

[9] J. Otani, T. Mukunoki, and Y. Obara, "Application of X-ray CT method for characterization of failure in soils," Soils and Foundation, vol. 40, no. 2, pp. 111-118, 2000.

[10] J. F. Bruchon, J. M. Pereira, M. Vandamme, N. Lenoir, P. Delage, and M. Bornert, "X-ray microtomography characterisation of the changes in statistical homogeneity of an unsaturated sand during imbibition," Géotechnique Letters, vol. 3, no. 2, pp. 84-88, 2013.
[11] D. H. Phillips and J. J. Lannutti, "Measuring physical density with X-ray computed tomography," NDT \&E International, vol. 30, no. 6, pp. 339-350, 1997.

[12] K. A. Alshibli, S. N. Batiste, R. A. Swanson, S. Sture, N. C. Costes, and M. R. Lankton, "Quantifying void ratio in sand using computed tomography," Geotechnical Measurements, vol. 106, pp. 30-43, 2000.

[13] K. Alshibli and A. Hasan, "Spatial variation of void ratio and shear band thickness in sand using X-ray computed tomography," Géotechnique, vol. 58, no. 4, pp. 249-257, 2008.

[14] J. A. Lafond, L. Han, S. E. Allaire, and P. Dutilleul, "Multifractal properties of porosity as calculated from computed tomography (CT) images of a sandy soil in relation to soil gas diffusion and linked soil physical properties," European Journal of Sport Science, vol. 63, no. 6, pp. 861-873, 2012.

[15] J. M. Wang, L. L. Guo, Z. K. Bai, and L. Yang, "Using computed tomography (CT) images and multi-fractal theory to quantify the pore distribution of reconstructed soils during ecological restoration in opencast coal-mine," Ecological Engineering, vol. 92, pp. 148-157, 2016.

[16] E. W. Tollner, N. D. Melear, L. A. Rodriguez, and M. E. Wright, "Soil aggregate size distributions using X-ray images," Transactions of the American Society of Agricultural Engineers, vol. 41, no. 4, pp. 1207-1215, 1998.

[17] L. B. Wang, J. Y. Park, and Y. R. Fu, "Representation of real particles for DEM simulation using X-ray tomography," Construction and Building Materials, vol. 21, no. 2, pp. 338-346, 2007.

[18] C. S. Chang, T. Matsushima, and X. Lee, "Heterogeneous strain and bonded granular structure change in triaxial specimen studied by computer tomography," Journal of Engineering Mechanics, vol. 129, no. 11, pp. 1295-1307, 2003.

[19] L. B. Wang, J. D. Frost, and J. S. Lai, "Three dimensional digital representation of granular material microstructure from X-ray tomography imaging," Journal of Computing in Civil Engineering, vol. 18, no. 1, pp. 28-35, 2004.

[20] K. A. Alshibli and B. A. Alramahi, "Microscopic evaluation of strain distribution in granular materials during shear," Journal of Geotechnical and Geoenvironmental Engineering, vol. 132, no. 1, pp. 80-91, 2006.

[21] Z. L. Cheng, L. P. Wu, and H. S. Ding, "Research on movement of particle of fabric of granular material," Rock and Soil Mechanics, vol. 28, pp. 29-33, 2007.

[22] Y. Watanabe, N. Lenoir, J. Otani, and T. Nakai, "Displacement in sand under triaxial compression by tracking soil particles on X-ray CT data," Soils and Foundations, vol. 52, no. 2, pp. 312-320, 2012.

[23] W. Sun, A X. Wu, K P. Hou, Y. Yang, L. Liu, and Y. Wen, "Real-time observation of meso-fracture process in backfill body during mine subsidence using X-ray CT under uniaxial compressive conditions," Construction and Building Materials, vol. 113, pp. 153-162, 2016.

[24] G. N. Hounsfield, "Computerized transverse axial scanning (tomography),” British Journal of Radiology, vol. 46, no. 552, pp. 11016-11022, 1973.

[25] Z. H. Chen, X. W. Fang, Y. Q. Zhu, B. Qin, and X. W. Wei, "Research on meso-structures and their evolution laws of expansive soil and loess," Rock and Soil Mechanics, vol. 30, no. 1, pp. 1-11, 2009.

[26] X. W. Fang, S. N. Shen, Z. H. Chen, and X. F. Huang, "Quantitative study of meso-structure evolution of intact Q2 loess during triaxial shear test," Rock and Soil Mechanics, vol. 31, no. 1, pp. 27-31, 2010. 
[27] R. E. Thomas and J. H. Richard, "A comparison of optical and $\mathrm{X}$-ray CT technique for void analysis in soil thin section," Geoderma, vol. 141, no. 1-2, pp. 60-70, 2007.

[28] T. Mukunoki, N. Kumano, and J. Otani, "Image analysis of soil failure on defective underground pipe due to cyclic water supply and drainage using X-ray CT," Frontiers of Structural and Civil Engineering, vol. 6, no. 2, pp. 85-100, 2012. 


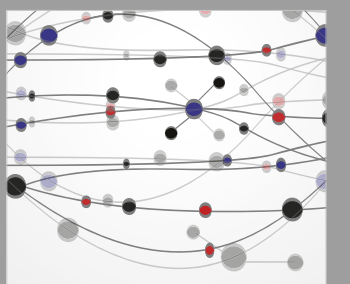

The Scientific World Journal
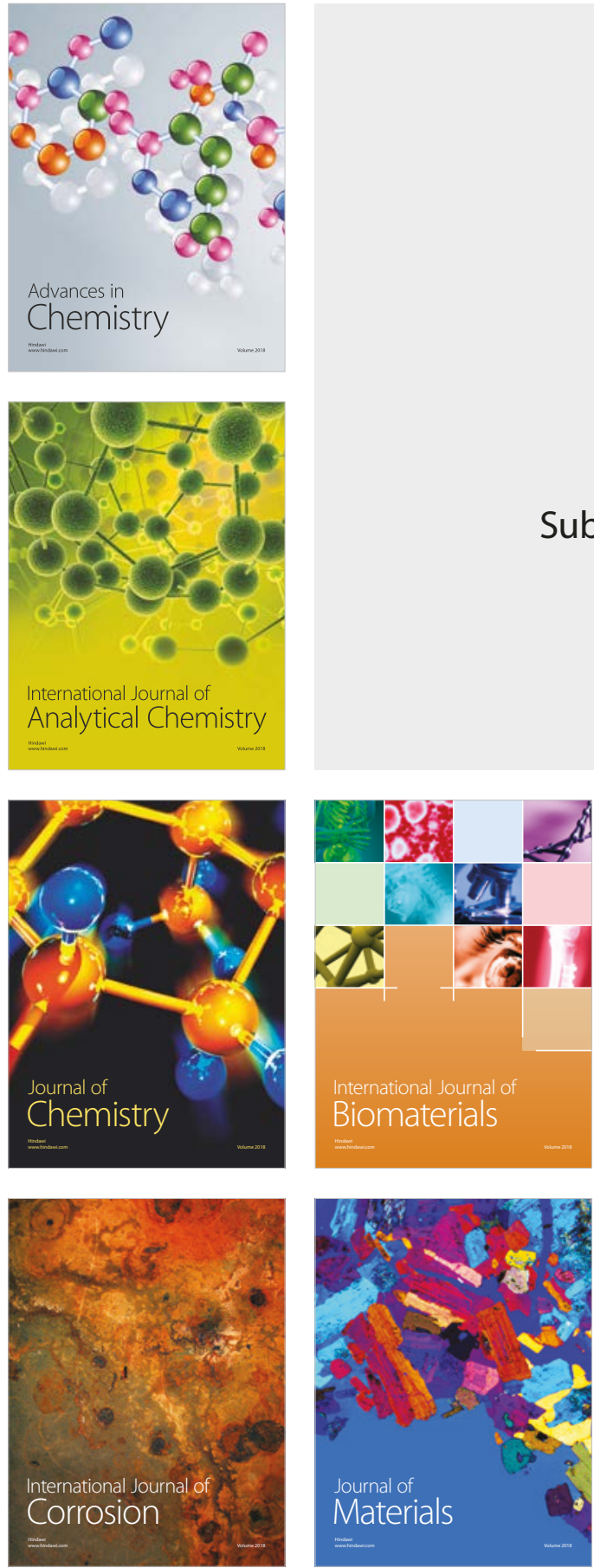

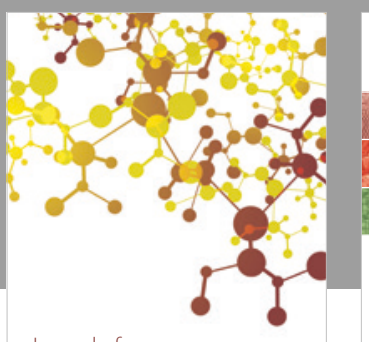

Journal of

Applied Chemistry
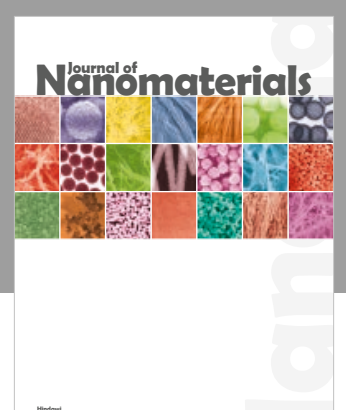

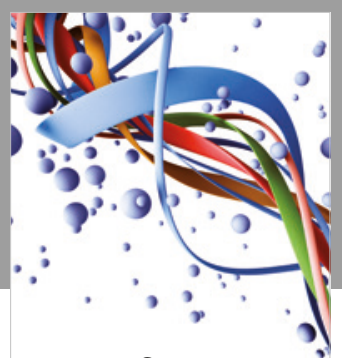

Scientifica

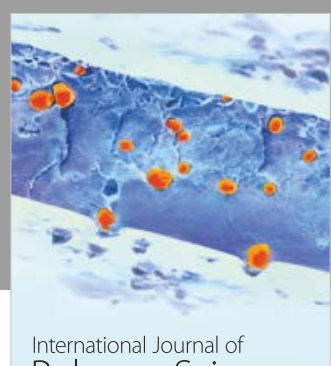

Polymer Science

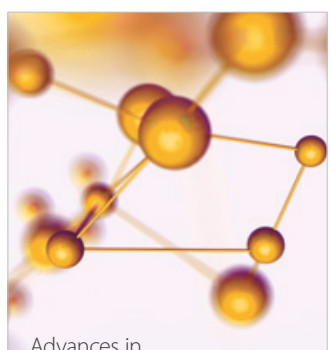

Physical Chemistry
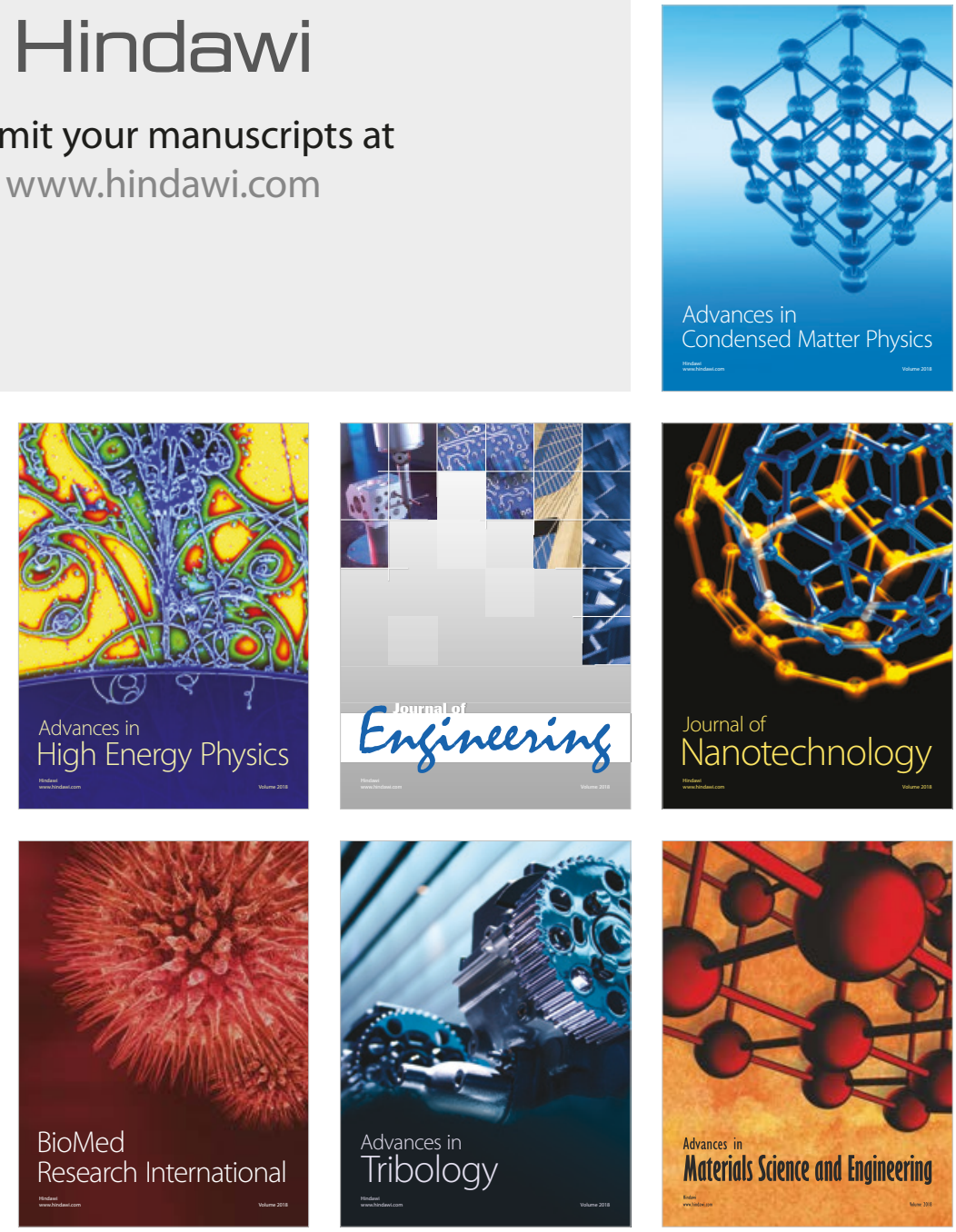